\title{
Transformações da paisagem e uso e ocupação das terras no município costeiro de Brejo Grande/Sergipe
}

\author{
Landscape transformations and use and occupation of land in the coastal \\ municipality of Brejo Grande/Sergipe
}

\author{
SANTANA ${ }^{1}$, B. L. P.; ALVES ${ }^{2}$, N. M. S.; SILVA ${ }^{3}$, D.B.; ANDRADE ${ }^{4}$, R.S.; \\ FARIAS ${ }^{5} ;$ M.C.V \\ bruna.leydiane@gmail.com
}

\section{Resumo}

A paisagem é resultado da interação entre fatores biofísicos e sociais, e se encontra em constante evolução. As alterações em um desses fatores implicam em ajustes nos demais, que compõem o sistema ambiental. Desse modo, o presente trabalho propõe uma análise das transformações ocorridas na paisagem do município costeiro de Brejo Grande/SE, com ênfase no uso e ocupação das terras. Para alcançar o referido objetivo os estudos foram norteados pela análise integrada, tendo como procedimentos metodológicos - pesquisa bibliográfica, análise de documentos cartográficos, trabalhos de campo e elaboração de mapas com técnicas de geoprocessamento. A análise efetuada confirma que as transformações na paisagem da área são consequências da atuação dinâmica de processos costeiros e fluviais, influenciados por ações antrópicas associadas às atividades produtivas, principalmente, a rizicultura, a carcinicultura e a cocoicultura.

Palavras-chave: dinâmica da paisagem, uso e ocupação das terras, atividades produtivas

\begin{abstract}
The landscape is the result of interaction between biophysical and social factors, and is constantly evolving. Changes in one of these factors imply adjustments in others, that make up the environmental system. Thus, this paper proposes an analysis of the transformations in the landscape of the coastal municipality of Brejo Grande / SE, with emphasis on the use and occupation of land. To achieve that objective studies were guided by integrated analysis, with the methodological procedures bibliographical research, analysis of cartographic documents, field work and preparation of maps with GIS techniques. The analysis performed confirms that the changes in the landscape of the area are the dynamic performance consequences of coastal and fluvial processes, influenced by human activities associated with productive activities, mainly to rice cultivation, shrimp farming and cocoicultura.
\end{abstract}

Keywords: landscape dynamics, use and occupation of land, productive activities

\section{INTRODUÇÃO}

A paisagem enquanto categoria de análise da Geografia se apresenta como resultado da interação estabelecida entre os componentes naturais - geologia, geomorfologia, clima, vegetação, hidrografia e solos - e a ação humana. A conjugação desses elementos constitui um sistema complexo, que exige ajustes permanentes.

Para Bertrand (2004, p.148), paisagem pode ser compreendida como uma "entidade global, admite-se implicitamente que os elementos que a constituem participam de uma dinâmica comum 
que não corresponde obrigatoriamente à evolução de cada um dentre eles tomados separadamente". Considerando-se que a paisagem é uma porção do espaço resultante da combinação dinâmica de elementos físicos, biológicos e antrópicos, que interagem uns sobre os outros, tornando a mesma um conjunto único e em permanente evolução (BERTRAND, 2004), pode-se afirmar que qualquer alteração nas relações entre os componentes do sistema ambiental irá se repercutir na sua dinâmica.

O funcionamento dos sistemas ambientais está propício a mudanças em razão de fatores que possam influenciar na relação dos fluxos energia/matéria, uma vez que, possui equilíbrio dinâmico. Neste contexto, os grupos sociais têm nas suas ações, potencial para desencadear alterações irreversíveis no meio ambiente. De acordo com o modo de vida e o nível tecnológico, cada grupo desenvolve distintos tipos de uso e manejo dos recursos naturais. As consequências dessas ações se tornam evidentes na descaracterização da paisagem. De modo geral, as intervenções antrópicas estão atreladas, sobretudo, às atividades produtivas.

Contudo, deve-se considerar que mudanças naturais ocorridas na paisagem também influenciam nas características econômicas, podendo favorecer a expansão de determinada atividade em função do declínio de outra, demonstrando a estreita relação entre a sociedade/natureza.

O município de Brejo Grande constitui-se de um mosaico de paisagens. Existem ambientes definidos pela dinâmica da ação dos processos naturais marinhos e fluviais, e outros caracterizados pela dinâmica social, em particular, aqueles relacionados com as atividades produtivas. Assim, o trabalho propõe analisar as transformações ocorridas na paisagem da referida área com ênfase no uso e ocupação das terras.

\section{METODOLOGIA}

O estudo se desenvolveu apoiado na análise integrada da paisagem e requereu a utilização dos seguintes materiais e procedimentos: pesquisa bibliográfica realizada em acervos virtuais de instituições e bibliotecas de universidades, na perspectiva de proporcionar embasamento teórico metodológico; levantamento e análise de documentos cartográficos do Projeto RADAMBRASIL (BRASIL, 1983), mapa da Geologia e Recursos Minerais do Estado de Sergipe, escala 1:250.000 (SANTOS et al., 1998) e o Mapa Exploratório - Reconhecimento de Solos do Estado de Sergipe, escala 1:500.000 (Silva, 2007); trabalhos de campo que possibilitaram a observação das características da paisagem - modelados, processos dinâmicos e diferentes tipos de uso das terras. Como produto cartográfico final, foi confeccionado o mapa de uso e ocupação das terras através da interpretação de fotografias áreas disponibilizadas pela Secretaria do Planejamento e da Ciência e 
Tecnologia do estado de Sergipe. A identificação dos tipos de uso foi feita a partir da interpretação visual diretamente na tela do computador, utilizando elementos básicos de interpretação, como cor, textura, forma, tonalidade, tamanho, sombra, padrão, adjacências e localização geográfica no Software ArcGis 10.1. Além disso, foi utilizada também a base cartográfica da Secretária de Recursos Hídricos de Sergipe.

\section{RESULTADOS E DISCUSSÃO}

\subsection{Localização e caracterização ambiental da área de estudo}

O município de Brejo Grande está inserido na porção norte do litoral Sergipano e no Território do Baixo São Francisco. Seu limite ao norte ocorre com o estado de Alagoas; a noroeste com o município de Ilha das Flores; a leste com o rio São Francisco, a oeste e sudoeste com Pacatuba e ao sul com o oceano Atlântico (Figura 01).

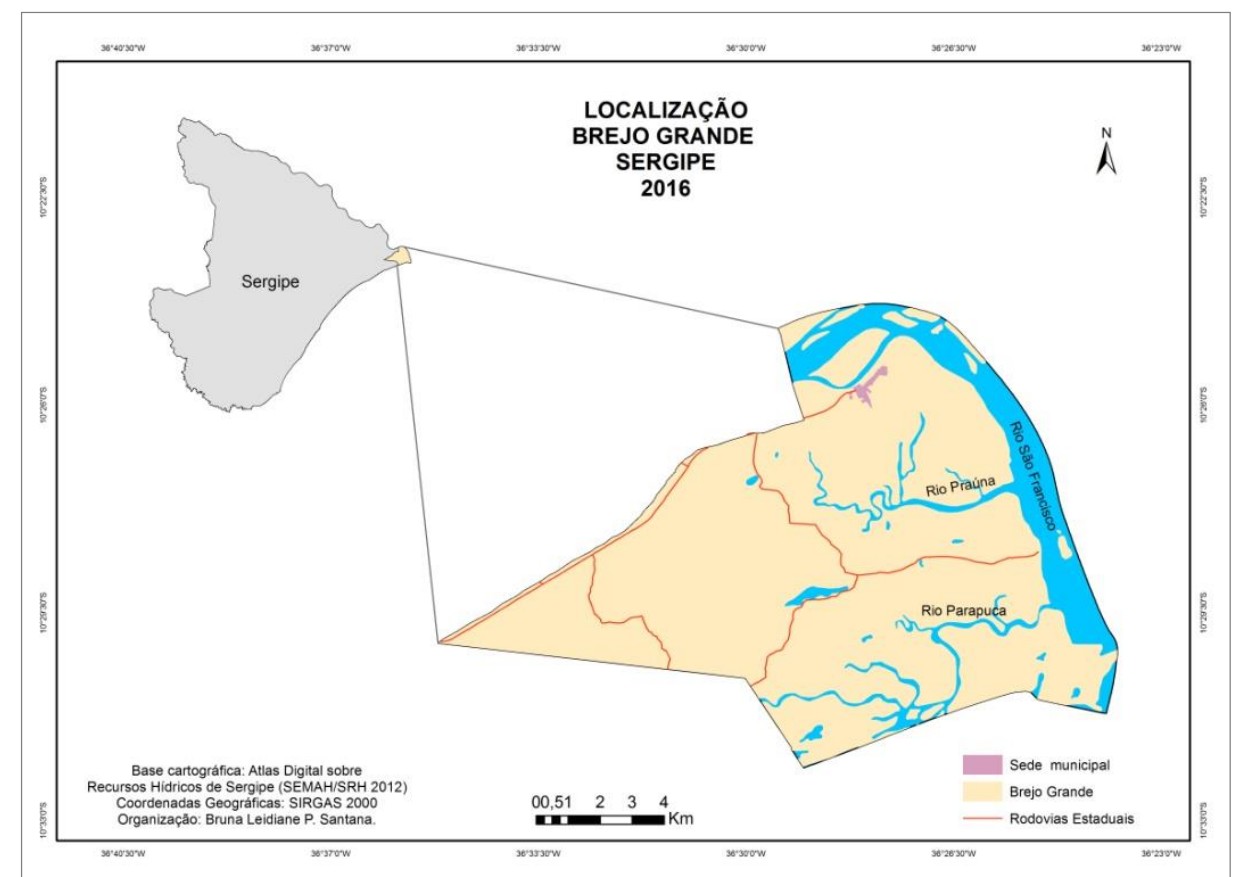

Figura 01. Mapa de localização da área de estudo. Fonte: Bruna L. P. Santana (2016)

Regionalmente, Brejo Grande encontra-se submetido ao clima Megatérmico Úmido/subúmido com temperatura média elevada, que varia entre $23,2^{\circ} \mathrm{C}$ e $28,8^{\circ} \mathrm{C}$, e a média anual está situada em torno de $25,0^{\circ} \mathrm{C}$. As precipitações concentram-se no período outono-inverno, com total pluviométrico anual de $1.300 \mathrm{~mm}$, aproximadamente. Os meses com menores índices correspondem às estações primavera e verão. (ALVES, 2010).

Geologicamente, a área é constituída por Formações Superficiais do Quaternário (SANTOS et al., 1998) abrangendo os Depósitos flúviolagunares formados por siltes argilosos e areia com 
presença de matéria orgânica, os Depósitos de pântanos e mangues compostos por sedimentos argilo-siltosos e matéria orgânica, submetidos às oscilações das marés, os Depósitos eólicos litorâneos relacionados com as dunas parabólicas colonizadas pela vegetação de restinga, e os sedimentos dos Terraços marinhos constituídos por areia média, grossa, cascalho e seixos.

Estas características geológicas remetem aos eventos climáticos do Quaternário que resultaram nas flutuações do nível marinho e possibilitaram o desenvolvimento de diferentes unidades geomorfológicas que integram a Planície Costeiro-Deltaica do Rio São Francisco Terraços marinhos holocênicos, Dunas costeiras inativas, Planície fluviolagunar e Planície fluviomarinha (ALVES, 2010).

Neste contexto, os Terraços marinhos holocênicos são feições caracterizadas pela variação de altitude entre 2 e 4 metros. Eles ocorrem associados a cordões litorâneos, que são linhas de costa pretéritas. Enquanto as Dunas costeiras inativas são morfologias com certa estabilidade morfodinâmica em razão de estarem colonizadas pela restinga herbácea. Elas ocupam uma grande área do município estendendo-se do povoado Brejão dos Negros à Carapitanga.

A Planície fluviolagunar presente em Brejo Grande é predominantemente de origem fluvial, formada de sedimentos finos argilosos e está sujeita a inundações periódicas. Por sua vez, a Planície fluviomarinha se encontra no ambiente de interação entre as águas marinhas e fluviais, onde a salinidade favoreceu o desenvolvimento da vegetação de mangue.

Associados a estas morfologias se desenvolveram os seguintes tipos de solos: os Gleissolos Háplicos encontrados na Planície fluviolagunar, apresentam textura média a argilosa, saturação hídrica e são oriundos do processo de gleização. Estes solos [...] "encontram-se permanente ou periodicamente saturados por água, salvo se artificialmente drenados. A água permanece estagnada internamente, ou a saturação é por fluxo lateral no solo" (EMBRAPA, 2006, p.80); os Neossolos Quartzarênicos ocorrem nos Terraços marinhos holocênicos e são caracterizados por textura arenosa e baixa fertilidade; os Neossolos Flúvicos estão presentes na Planície fluviolagunar, são compostos por sedimentos fluviais e matéria orgânica, que lhes conferem boas condições de fertilidade, e os Solos Indiscriminados de Mangue, frequentes na Planície fluviomarinha, apresentam coloração escura, salinidade elevada e evolução pedogenética recente restringindo o uso agrícola.

O conjunto florístico da paisagem é constituído por Formações Pioneiras com espécies características dos ambientes de Áreas de Influência Marinha - a Restinga, de Influência Fluviomarinha - o Mangue e de Influência Fluvial - os Campos de Várzea.

A área de estudo possui grande disponibilidade de recursos hídricos, pois integra a bacia hidrográfica do rio São Francisco, sendo este seu principal canal fluvial. Os rios Paraúna e Parapuca 
também compõem a hidrografia local. Eles apresentam padrões meândrico e anastomosado, que também caracterizam o rio São Francisco nas proximidades da sede de Brejo Grande devido a existência de pequenas ilhas no leito.

\subsection{Transformações da paisagem e sua relação com o uso e ocupação das terras}

A paisagem do município de Brejo Grande caracteriza-se pela a ocorrência de diferentes feições morfológicas e ambientes, resultantes da interação dos processos fluviais e costeiros, que favoreceram a determinados tipos de uso e ocupação das terras. A exploração econômica dos recursos ambientais contribuiu para as transformações ocorridas na paisagem. Elas são, sobretudo, produto da interação entre os processos oceanográficos, climáticos e fluviais, que atuam em um ambiente formado por um mosaico geomorfológico, e as técnicas de manejo empregadas nas atividades produtivas principais - rizicultura, carcinicultura, cocoicultura, pecuária extensiva (Figura 02).

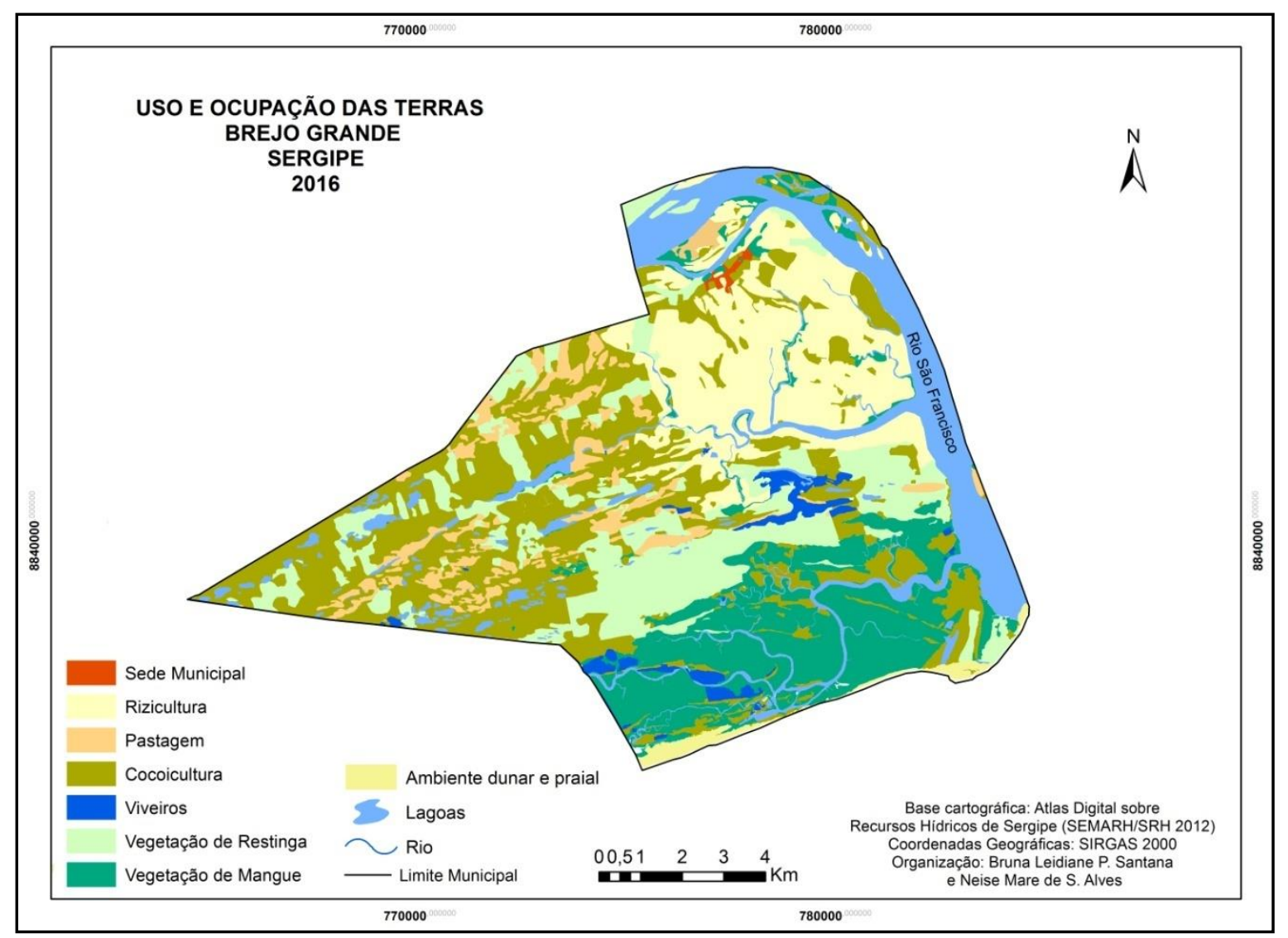

Figura 02. Mapa de uso e ocupação das terras do município de Brejo Grande/Sergipe. Fonte: Bruna L. P Santana;

Neise Mare S. Alves (2016)

$\mathrm{Na}$ atualidade, as transformações da paisagem se traduzem em problemas ambientais, a exemplo da erosão nas margens e na foz do rio São Francisco, bem como no avanço de sedimentos 
arenosos dos terraços sobre setores da Planície fluviomarinha, aterrando parcialmente a vegetação de Mangue, na Barra da Costinha. Essas ocorrências são atribuídas às interferências antrópicas ao longo do canal do rio São Francisco, com a construção de barragens, particularmente às hidrelétricas de Sobradinho e Xingó que proporcionaram a redução do aporte sedimentar e do volume de água no canal de drenagem do rio referido. A modificação sobre a hidrodinâmica do sistema fluvial tem consequências sobre os processos costeiros, pois a ação dos mesmos tem se intensificado na foz, se refletindo na estabilidade das feições morfológicas que compõem a paisagem.

Quanto às atividades produtivas, historicamente, Brejo Grande teve sua ocupação marcada pela expansão cana-de-açúcar no Nordeste brasileiro. Contudo, as inundações periódicas nas áreas de plantio associada à concorrência do açúcar de beterraba no mercado internacional favoreceram o seu declínio (SOUTO, 2003, p.110), cedendo lugar para a rizicultura desenvolvida na Planície fluviolagunar do rio São Francisco. As condições ambientais permitiram que esta atividade alcançasse resultados positivos por muitos anos.

Nas décadas de 1930 e 1940, o cultivo de arroz ocupava as várzeas que eram atingidas pelas inundações do rio São Francisco periodicamente, e, que cessaram após a regularização da vazão. Essa mudança tornou inviável manter a atividade em algumas áreas, tanto pela deficiência hídrica e de nutrientes, como pela salinização das águas fluviais, nos dias atuais, em razão do avanço da cunha salina. O elevado teor de sal prejudica o crescimento do grão de arroz, comprometendo a produtividade.

A regularização da vazão do sistema fluvial na área contribuiu para que, hoje, a rizicultura se desenvolva com aplicação da técnica de irrigação por inundação, realizada através do controle artificial dos pequenos cursos de água e riachos da Planície fluviolagunar. A utilização dessa técnica resultou na desestruturação da rede de drenagem, acarretando no processo de assoreamento em setores dos canais fluviais.

Os problemas relacionados à rizicultura influenciaram a nova reorientação econômica em Brejo Grande, pois as antigas lagoas destinadas ao cultivo do arroz passaram a ser ocupadas por viveiros de camarão marinho devido a sua salinização. No entanto, a expansão da carcinicultura tem alcançado as áreas do Mangue, resultando no desmatamento da vegetação e descaracterização da paisagem (Figura 03). 


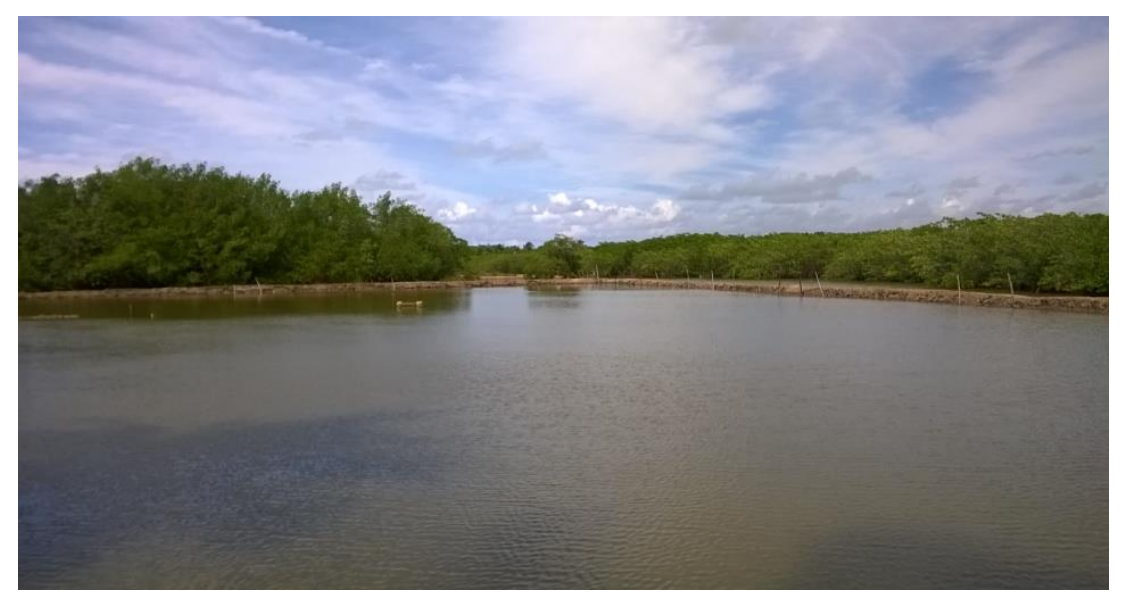

Figura 03. Viveiro de camarão instalado em mangue - Povoado Carapitanga Brejo Grande/SE. Fonte: Bruna L. P. Santana (2016)

O declínio da rizicultura e a expansão da carcinicultura imprimem na paisagem novos processos de produção do espaço. Dentre estes, ressaltam-se mudanças na utilização das técnicas de manejo, o surgimento de possíveis problemas ambientais com a introdução de espécie exótica no ecossistema aquático e o impacto sobre a condição de renda das famílias inseridas na cadeia produtiva, seja ela negativa ou positiva. Segundo o relato de carcinicultores, a atividade possibilita obter maior lucro em relação à pesca artesanal e à cata de mariscos. Entretanto, menos mão-de-obra é necessária para a atividade, reduzindo os postos para o trabalhador rural.

A paisagem de Brejo Grande é constituída por uma rede de drenagem que propicia o desenvolvimento da pesca artesanal e a cata de crustáceos e mariscos como o caranguejo-uçá, dedode-moça e sururu. $\mathrm{O}$ estabelecimento de comunidades às margens do rio São Francisco evidência a importância dessas atividades no processo de ocupação das terras.

Assim como na rizicultura, o processo de salinização das águas fluviais tem impactado de forma negativa também a pesca artesanal. Os pescadores alegam que houve redução da população de peixes de água doce, sendo possível encontrar espécies do ambiente marinho nos rios. Em função disso, eles têm buscado outras formas de complementar a renda familiar. Uma alternativa tem sido a apicultura, uma atividade que não compromete os recursos naturais, oferecendo condições de sustentabilidade ambiental e social.

Dentre as atividades estabelecidas no território de Brejo Grande, a cocoicultura, destaca-se porque costuma ser associada a outras, como à rizicultura, carcinicultura e pecuária extensiva. Geralmente, para fixar os sedimentos dos "muros" - espécie de diques construídos para separar os viveiros de camarão ou as lagoas de arroz - coqueiros são plantados sobre eles. Por outro lado, há locais em que o cultivo do coco-da-baía ocupa as áreas de ocorrência da Restinga herbácea e arbustiva, reduzindo essa vegetação nativa e descaracterizando a paisagem. No ano 2000, o 
município de Brejo Grande concentrou $6 \%$ da produção estadual de coco-da-baía, com área cultivada de 45.720 ha (EMBRAPA, 2008).

A cocoicultura ocorre associada também à agricultura de subsistência, que está representada basicamente pela produção de mandioca, feijão, batata-doce e milho. Na paisagem são encontradas pequenas áreas destinadas à plantação desses gêneros. A deficiência nutricional dos solos restringe o uso das terras para as práticas agrícolas.

Além das transformações na paisagem provocadas pelo desenvolvimento das atividades produtivas abordadas, há a extração mineral realizada nas dunas costeiras inativas. A retirada dos sedimentos arenosos nessas feições propicia a reativação de processos eólicos, em função supressão da vegetação nativa e com isso amplia-se a descaracterização paisagística na área (Figura 04).

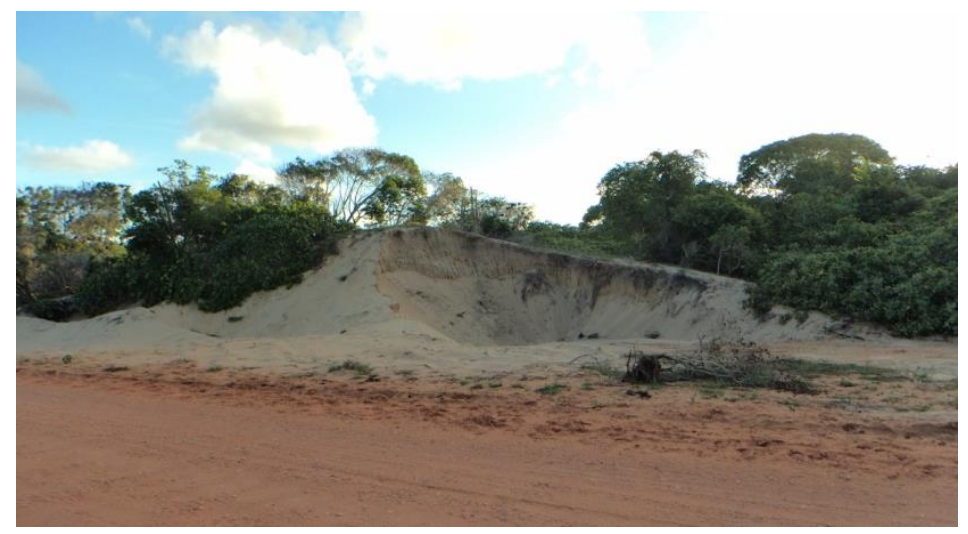

Figura 04. Duna costeira inativa com evidência de extração mineral nas proximidades do povoado Carapitanga/SE. Fonte: Neise Mare S. Alves (2016)

Na Planície fluviolagunar os cultivos tradicionais - arroz e coco-da-baía - dividem espaço com o campo de exploração da Petrobras, que inclui coleta de petróleo e gás. Esta atividade tem repercussões no contexto político, social e, principalmente, econômico do município, a partir do recebimento dos royalties.

\section{CONSIDERAÇÕES FINAIS}

Os procedimentos metodológicos e as bases teóricas adotadas permitiram compreender a dinâmica que domina o sistema ambiental físico da paisagem do município de Brejo Grande e as transformações que ocorrem no ambiente relacionadas com o uso e ocupação das terras.

Os condicionantes climáticos, geológicos, geomorfológicos e hidrográficos em interação permanente contribuíram para a formação de morfologias, ambientes e ecossistemas que favoreceram o desenvolvimento de certas atividades produtivas. Por outro lado, na atualidade, as 
intervenções antrópicas alteraram a hidrodinâmica do rio São Francisco e, consequentemente, novos tipos manejos foram adotados para que as atividades continuem. Essas mudanças têm contribuído para que sejam observadas transformações irreversíveis na paisagem do município de Brejo Grande.

As transformações identificadas como o retrogradação na linha de costa, intensificação da mordodinâmica sobre as margens dos cursos de água e dunas costeiras inativas são, portanto, resultado da conjugação da dinâmica natural fortemente subordinada aos processos do sistema fluvial e marinho, com as interferências antrópicas decorrentes da apropriação dos recursos naturais, com o uso e ocupação das terras.

\section{REFERÊNCIAS}

ALVES, Neise Mare S.. Análise geoambiental e socioeconômica dos municípios costeiros do litoral norte do estado de Sergipe - Diagnóstico como subsídio ao ordenamento e gestão do território. Tese de doutorado apresentado ao Núcleo de Pós-Graduação em Geografia, Pró-Reitoria de Pós-Graduação e Pesquisa, Universidade Federal de Sergipe, 2010.

BERTRAND, G. Paisagem e geografia física global: esboço metodológico. R. RA`E GA, Curitiba, n. 8, p. 141-152, 2004.

BRASIL. Ministério das Minas e Energia. Projeto RADAMBRASIL: folha SC.24/25 Aracaju/Recife: geologia, geomorfologia, pedologia, vegetação, uso potencial da terra. Rio de Janeiro, 1983. 851 p. (Levantamento de Recursos Naturais, 30).

EMBRAPA. Realocação Espacial da Cocoicultura nos Principais Municípios Produtores do Estado de Sergipe; 1990, 1995, 2000 e 2005. Embrapa Tabuleiros Costeiros Aracaju, 2008. .Sistema brasileiro de classificação de solos. 2. ed. - Rio de Janeiro : EMBRAPASPI, 2006.

SANTOS, R. A. dos. (Org.). et al. Geologia e recursos minerais do estado de Sergipe: texto explicativo do mapa geológico do estado de Sergipe. Brasília: CPRM; Aracaju: CODISE, 107 p. 1998. (Programa Levantamentos Geológicos Básicos do Brasil). 
SOUTO, Paulo Henrique. Litoral norte sergipano: História e perspectivas sócio-econômicas.

Dissertação de mestrado apresentado ao Núcleo de Pós-Graduação em Geografia, Pró-Reitoria de Pós-Graduação e Pesquisa, Universidade Federal de Sergipe, 2003.

\section{AGRADECIMENTOS}

Estes estudos foram desenvolvidos com bolsa PIBIX, apoio financeiro da Pró-Reitoria de Extensão, da Universidade Federal de Sergipe.

Recebido em: 14/08/2016

Aceito para publicação em: 01/10/2016 